\title{
Incorporating on-campus days in a graduate apprenticeship.
}

\author{
YOUNG, T., ZARB, M.
}

2019

(C) ACM, 2019. This is the author's version of the work. It is posted here by permission of ACM for your personal use. Not for redistribution. The definitive version was published in Proceedings of the 24th Innovation and technology in computer science education (ITICSE 2019) http://doi.acm.org/10.1145/3304221.3325567. 


\section{Incorporating On-Campus Days in a Graduate Apprenticeship}

\author{
Tiffany Young \\ School of Computing Science and Digital Media \\ Robert Gordon University \\ Aberdeen, United Kingdom \\ t.young3@rgu.ac.uk
}

\author{
Mark Zarb \\ School of Computing Science and Digital Media \\ Robert Gordon University \\ Aberdeen, United Kingdom \\ m.zarb@rgu.ac.uk
}

\begin{abstract}
Graduate Apprenticeships look to overcome the segregation of learning and working by integrating traditional education into the context of the work environment. This poster looks to highlight the importance of peer interactions, specifically for Online Distance Learners and how Robert Gordon University has implemented this within its GA programmes through on-campus days.
\end{abstract}

\section{CCS CONCEPTS}

- Social and professional topics $\rightarrow$ Computing education.

\section{KEYWORDS}

Graduate Apprenticeship, Work-Based Learning, Support Student Success, Online Distance Learning, On-Campus Days, Community of Practice

\section{INTRODUCTION}

Graduate Apprenticeships (GA) look to combine academic knowledge and qualification recognition along with practical skills development. Scotland's inaugural year for GAs started in 2017 which saw Robert Gordon University (RGU), along with other Scottish institutions, partake in the industry-led delivery. The apprentices are full-time work-based learners (WBL) supported by their employers, whilst also studying full-time in an academic distance learning environment. This collaborative approach looked to more closely align graduates skills and knowledge with industry needs.

Previous research [1] shows that WBL are likely to be a member of a work-based Community of Practice within their workplace prior to becoming a Graduate Apprentice. Community of Practices $(\mathrm{CoP})$ are "groups of people who share a concern or a passion for something they do and learn how to do it better as they interact regularly" [2]. Building an additional CoP within RGU was recognised as an important objective to allow these apprentices to benefit from peer interactions with others working towards the same qualification.
Whilst the apprentices were given the option of communicating through weekly online interactive sessions and through collaborative tools such as Microsoft Teams, to further promote engagement and facilitate access to additional support, the course team felt that face-to-face interactions were required. Informal peer discussions tend to occur naturally when students are physically located oncampus, as traditional students usually are, but for these distance learning apprentices, this is something that requires more planning and coordination. To promote peer discussions between apprentices, the addition of on-campus contact sessions with students was organised.

In 2018, the second year of Graduate Apprenticeships for RGU, face-to-face sessions were developed to supplement the Online Distance Learning (ODL) delivery. These on-campus days facilitated peer interactions and encouraged the development of a supportive learning environment which proved beneficial to encourage engagement and promote support whilst allowing the students to build meaningful relationships with one another. As Vygotsky theorises, the creation of a supportive learning community would further enhance the students learning experience and provide access to more experienced and capable learners [2].

\section{STRUCTURE OF ON-CAMPUS DAYS}

Each academic year within the GA, as run by The School of Computing Science and Digital Media (CSDM), consists of four ten-weeklong modules, each of which runs one on-campus day. Each module runs sequentially and the on-campus days are located in the middle of the delivery. This was to allow academic staff to meet with the apprentices face-to-face and highlight any potential difficulties encountered and implement any measures to mitigate these.

\section{INITIAL RESULTS AND FUTURE WORK}

As a result of these on-campus days, it is clear that apprentices are more engaged with their modules and have developed a familiarity with each other which was lacking in the previous run of the course. Apprentices found that these sessions helped them to connect with the student body and felt more involved with the student experience as a whole. RGU are in discussion to determine if the addition of more on-campus days would be beneficial to apprentices going forward.

\section{REFERENCES}

[1] Ruth Helyer. 2016. Editorial. Higher Education, Skills and Work-Based Learning 6, 3 (2016). https://doi.org/10.1108/heswbl-06-2016-0044

[2] Jean Lave and Etienne Wenger. 1991. Legitimate Peripheral Participation. Situated Learning (1991), 27âĂŞ44. https://doi.org/10.1017/cbo9780511815355.003 